\title{
El principio de inmediación y la actividad probatoria en la normativa procesal ecuatoriana
}

\section{The principle of immediacy and probative activity in the Ecuadorian procedural law}

\author{
Rita Ximena Gallegos Rojas \\ Universidad Internacional del Ecuador, Ecuador
}

Autor para correspondencia: rigallegosro@uide.edu.ec

Fecha de recepción: 21 de febrero del 2019 - Fecha de aceptación: 15 de abril del 2019

Resumen: El principio de inmediación en el sistema procesal oral implica la interacción del juez en la recepción de la prueba, las partes, testigos y peritos, permitiendo una decisión judicial, con la información de calidad obtenida en la audiencia. Sin embargo, qué sucede cuando los jueces que intervinieron en la actividad probatoria, que dieron su decisión oral, no pueden intervenir en la elaboración y suscripción de la sentencia, acaso otros jueces, tendrían que declarar la nulidad de lo actuado y realizar una nueva audiencia de juicio para inmediar con la prueba, o a través de los medios magnetofónicos, otros jueces pueden elaborar la sentencia. Frente a esta situación, la otrora Corte Suprema de Justicia emitió la Resolución No. 564, de 26 de octubre de 2011, y la actual Corte Nacional de Justicia expidió la Resolución No. 18-2017 de 22 de noviembre del 2017, por lo que, el eje central del presente trabajo, que emplea una investigación cualitativa radica en determinar si las citadas resoluciones, vulneran el principio de inmediación probatoria en el Código Orgánico General de Procesos y en el Código Orgánico Integral Penal, abordando este problema a través de un estudio analítico, doctrinal, normativo, comparativo y jurisprudencial, recurriendo a una metodología descriptiva que tiene como objeto identificar el problema central a través de fuentes legales.

Palabras claves: inmediación; nulidad; sistema oral; ausencia de juez.

\begin{abstract}
The principle of immediacy in the oral procedural system involves the interaction of the judge in the reception of the evidence, the parties, witnesses and experts, allowing a judicial decision, with the quality information obtained at the hearing. However, what happens when the judges who took part in the probative activity, who gave their oral decision, can not intervene in the elaboration and subscription of the sentence, perhaps other judges, would have to declare the nullity of the proceedings and make a new hearing of judgment to mediate with the test, or through the recording media, other judges can elaborate the sentence. Faced with this situation, the former Supreme Court of Justice issued Resolution No. 564 of October 26, 2011, and the current National Court of Justice issued Resolution No. 18-2017 of November 22, 2017, for which, the central axis of this work, which employs a qualitative research is to determine whether the aforementioned resolutions, violate the principle of probative immediacy in the General Organic Code of Processes and the Organic Comprehensive Criminal Code, addressing this problem through a study analytical, doctrinal, normative, comparative and jurisprudential, using a descriptive methodology that aims to identify the central problem through legal sources.
\end{abstract}

Key Words: immediacy; nullity; oral system; absence of judge. 


\section{Introducción}

La implementación del sistema oral en la normativa procesal ecuatoriana fue un mandato de las Constituciones de 1998 y 2008, aunque las cartas fundamentales de 1945, 1967, 1979, disponían que las leyes procesales “adoptarán en lo posible el sistema oral”, sin embargo, recién se hizo efectivo en material civil desde la promulgación y entrada en vigor del Código Orgánico General de Procesos a partir del 22 de mayo del 2016, mientras que en materia penal la oralidad entró en vigencia en el año 2001.

El sistema procesal oral se basa en los principios dispositivo, inmediación, concentración, contradicción, publicidad y celeridad.

Para Guillermo Cabanellas, inmediación es principio de derecho procesal encaminado a la relación directa de los litigantes con el juez, prescindiendo de la intervención de otras personas. Constituye el medio de que el magistrado conozca personalmente a las partes y pueda apreciar mejor el valor de las pruebas, especialmente de la testifical, ya que todas ellas han de realizarse en su presencia (Cabanellas de Torres, 2012).

La inmediación a más de constituir uno de los principios fundamentales del sistema oral y de la actividad probatoria, implica:

Un contacto directo entre el juez, las partes, terceros intervinientes y las pruebas, a fin de permitir la solución más adecuada y depuración más precisa de los hechos, lo que permite la observancia de los principios de la convicción racional del juez, de la inmediatez, de la publicidad, de la concentración y del incremento de los poderes instructores del juez (Martínez Lina \& Diaz Laura, 2009).

Devis Echandia refiere que debe haber una inmediata comunicación entre el juez y las personas que obran en el proceso y los hechos que en él deben constar (Devis, Nociones Generales de Derecho Procesal Civil, 2009).

Muy diferente a lo que sucede en el sistema escrito, en el cual el juez es un mero lector de lo argumentado por las partes, "donde se extiende la delegación reservándose el juez prácticamente solo para la dictación de la sentencia” (Palomo D. , 2009), ya que puede delegar a otra autoridad judicial o administrativa la recepción de pruebas, sin mediar con las partes, testigos, ni peritos, convirtiéndose en un juez pasivo.

No obstante, qué sucede si los jueces que intervinieron en la actividad probatoria, que dieron su decisión oral, no pueden intervenir en la elaboración y suscripción de la sentencia, acaso otros jueces, tendrían que declarar la nulidad de lo actuado y realizar una nueva audiencia de juicio para mediar con la prueba, o a través de los medios magnetofónicos, otros jueces podrían elaborar la sentencia, frente a esto, la otrora Corte Suprema de Justicia del Ecuador, en materia penal, emitió la Resolución de 5 de octubre de 2011, relacionada con la forma de proceder cuando alguno de los jueces que intervino en la audiencia oral, no pudiera firmar la sentencia "misma que, debido al nuevo ordenamiento jurídico vigente en el Ecuador tanto en materias penales como no penales, resulta caduca", conforme lo señala la misma. 
Fundamentándose que esta resulta caduca, se expidió la Resolución No. 18-2017 de 22 de noviembre del 2017, por lo que, el eje central del presente trabajo radica en contestar la siguiente interrogante: determinar si las citadas resoluciones vulneran el principio de inmediación probatoria en el Código Orgánico General de Procesos y en el Código Orgánico Integral Penal, abordando este problema a través de un estudio crítico, doctrinal, normativo y revisión de fallos tanto de la Corte Nacional de Justicia y tribunales inferiores.

Este trabajo lo conforman tres secciones: En la primera sección se abordará, las generalidades del sistema procesal oral, luego en la segunda sección, se examinará la naturaleza jurídica del principio de inmediación en la actividad probatoria; en la tercera sección, se analizará las resoluciones adoptadas por la Corte Nacional de Justicia, en los casos de ausencia temporal o definitiva de los jueces que intervinieron en la audiencia de juicio, pero no pudieron firmar la sentencia, además de las decisiones judiciales emitidas por la misma Corte Nacional y otras cortes inferiores en relación a esta problemática, antes de dictarse dichas resoluciones y su incidencia en el principio de inmediación en el sistema procesal, por último se expondrán las conclusiones finales.

\section{Metodología}

Este trabajo consiste en una investigación de carácter descriptiva amparada en el método comparado, por cuanto analiza el principio de inmediación a la luz del sistema oral tanto en la normativa procesal ecuatoriana, en la que se incluyen el Código Orgánico General de Procesos como el Código Orgánico Integral Penal, así como en los estudios doctrinarios efectuados sobre el tema y tiene como objetivo contrastar los fundamentos del principio de inmediación en la actividad probatoria con las resoluciones adoptadas en este sentido por la Corte Nacional de Justicia, cuando un juez se ausenta por cualquier causa, luego de la resolución dictada en forma oral, sin poder elaborar ni suscribir la sentencia. Este trabajo utiliza referencias bibliográficas como la Constitución del Ecuador, las normas procesales, la jurisprudencia de la Corte Nacional de Justicia antes de la expedición de la Resolución No. 18-2017 de 22 de noviembre del 2017.

\section{Generalidades del Sistema Procesal Oral}

En los últimos veinte años América Latina ha experimentado un proceso muy intenso de reformas judiciales que han transformado bastante radicalmente los sistemas judiciales de la mayoría de los países. En una primera etapa los esfuerzos se concentraron en reformar la justicia criminal, más recientemente se han orientado a modernizar el otro lado del sistema judicial que aún estaba pendiente, que es la justicia civil. (Centro de Estudios de Justicia de las Américas, 2013, pág. 7).

Es así que Ecuador, instauró un sistema de justicia procesal penal basado en la oralidad que entró en vigencia en el 2001, mientras que a partir del 22 de mayo del 2016, entró en vigor el Código Orgánico General de Procesos, cuyo ámbito de aplicación son las materias civiles, en las que se incluyen niñez, laboral, contencioso administrativo y tributario, inquilinato, etc., excepto la constitucional, electoral y penal. 
El sistema oral frente al sistema escrito tiene ciertas ventajas, porque existe una acentuada comunicación entre el juez y las partes. La prueba oportunamente anunciada y admitida se practica en audiencia oral pública y contradictoria. Las resoluciones por lo general, se dictan en audiencia ${ }^{1}$, todo esto en base a los principios de concentración, contradicción, inmediación, dispositivo y publicidad. Además, permite que las partes se preparen para argumentar sus pretensiones y centrar sus debates, así como el rol del juez cambia constituyéndose en director de la audiencia con sus facultades y limitaciones, entre estas últimas tenemos: no obtener información de testigos y peritos sino únicamente formular aclaraciones a fin que se mantenga su papel de juez independiente e imparcial.

La concentración refiere a la posibilidad de realizar los actos probatorios en la audiencia de juicio, si es posible de forma continua y en días consecutivos, salvo asuntos de declaraciones urgentes de las personas que por su avanzada edad o grave enfermedad se teman fundadamente puedan fallecer, o de quienes están próximos a ausentarse del país, que se pueden receptar anticipadamente.

En cuanto a la contradicción, esta se presenta cuando las partes contradicen las afirmaciones, pretensiones o pruebas presentadas por la contraparte, se debe brindar oportunidad igual a las partes de participar efectivamente en la relación dialéctica, en la actividad de administración de justicia, este método de igual oportunidad de acción y de contradicción es el que debe seguirse para buscar la verdad material en el proceso (Zabaleta, 2017).

El principio dispositivo constituye un pilar fundamental del proceso civil, en virtud del cual se entiende que la tutela jurisdiccional de los derechos e intereses solo puede iniciarse a petición de parte (Aguirrezabal, 2017). Sin embargo, el Art. 168 del Código Orgánico General de Procesos dispone que el juzgador podrá, excepcionalmente, ordenar de oficio y dejando expresa constancia de las razones de su decisión, la práctica de la prueba que juzgue necesaria para el esclarecimiento de los hechos controvertidos. Por este motivo, la audiencia se podrá suspender hasta por el término de quince días.

La publicidad permite que terceros conozcan la intervención de los sujetos procesales, peritos y testigos y la resolución del juzgador con el fin de fortalecer la transparencia en las decisiones judiciales

Proceso oral por audiencias, cuya sustanciación en todas las instancias, fases y diligencias se desarrollarán mediante el sistema oral, salvo los actos procesales que deban realizarse por escrito. Las audiencias podrán realizarse por videoconferencia u otros medios de comunicación de similar tecnología, cuando la comparecencia personal no sea posible, conforme lo dispone el Artículo 4 del Código Orgánico General de Procesos; mientras que el Artículo 5 numeral 11, del Código Orgánico Integral Penal expresa, que: el proceso se desarrollará mediante el sistema oral y las decisiones se tomarán en audiencia; se utilizarán los medios técnicos disponibles para dejar constancia y registrar las actuaciones procesales; y, los sujetos procesales recurrirán a medios escritos en los casos previstos en este Código

\footnotetext{
1 Aunque hay ciertas excepciones como la prevista en el Art. 93 del Código Orgánico General de Procesos, pues dependiendo de la complejidad del caso, el juzgador podrá suspender la audiencia por el término de diez días para emitir su decisión oral
} 


\section{Naturaleza jurídica del principio de inmediación}

La inmediación en un juicio oral, como expresan Mauricio Duce y Andrés Baytelman: Supone que el tribunal debe recibir y percibir en forma personal y directa la prueba, y que su recepción y percepción debe obtenerse a partir de su fuente directa. De este modo, salvo casos muy excepcionales, los testigos y peritos deberán comparecer personalmente al juicio para declarar y ser examinados y contraexaminados directamente por las partes, sin permitirse la reproducción de sus declaraciones anteriores por medio de su lectura (Duce, 2004). Roxin señala que:

"[el principio de inmediación importa que el juez debe elaborar la sentencia de acuerdo con las impresiones personales que obtiene del acusado y de los medios de prueba; así, p. ej., la declaración de los testigos no puede ser reemplazada, en principio, por la lectura de un acta que ha sido labrada por un juez comisionado o por exhorto [...]. (Roxin, 2008, pág. 135)

La inmediación hace relación con el derecho a ser oído, previsto en el artículo 8.1 de la Convención Americana de Derechos Humanos, que expresa: 1. Toda persona tiene derecho a ser oída, con las debidas garantías y dentro de un plazo razonable, por un juez o tribunal competente, independiente e imparcial, establecido con anterioridad por la ley, en la sustanciación de cualquier acusación penal formulada contra ella, o para la determinación de sus derechos y obligaciones de orden civil, laboral, fiscal o de cualquier otro carácter. Esto significa que a través de un proceso escrito, no se puede garantizar plenamente este derecho, esto por cuanto; en la inmediación propia del sistema oral se presenta "una interacción directa e inmediata entre las partes y el juez de la causa en el examen y contraexamen de las pruebas del proceso, y por ello, la decisión judicial se fundamenta en la información que fue recepcionada en audiencia." (Pereira Santiago, 2011).

La inmediación como principio procesal en el Código Orgánico Integral Penal, se encuentra previsto en el Artículo 5 numeral 17: Inmediación: la o el juzgador celebrará las audiencias en conjunto con los sujetos procesales y deberá estar presente con las partes para la evacuación de los medios de prueba y demás actos procesales que estructuran de manera fundamental el proceso penal.

Mientras que el Código Orgánico General de Procesos sobre la inmediación, establece en su Artículo 6, que la o el juzgador celebrará las audiencias en conjunto con las partes procesales que deberán estar presentes para la evacuación de la prueba y demás actos procesales que estructuran de manera fundamental el proceso. Sólo podrán delegar las diligencias que deban celebrarse en territorio distinto al de su competencia. Las audiencias que no sean conducidas por la o el juzgador serán nulas.

La primera parte de esta disposición es muy semejante a lo previsto en el Código Orgánico Integral Penal, la diferencia con el Código Orgánico General de Procesos, radica que sólo pueden delegarse ciertas diligencias, tal como lo expresa el Artículo 72 Ibídem, que el juzgador podrá ordenar la práctica de alguna diligencia mediante deprecatorio o comisión a otra 
u otro juzgador dentro del territorio nacional. Esta facultad no incluye la realización de audiencias ni la práctica de pruebas.

El principio de la inmediación posibilita la elaboración de decisión que esté de acuerdo con la realidad del caso concreto, ya que esa proximidad de las partes permite una mejor reconstrucción de los hechos. (Martínez, 2009)

Empero, existe una excepción a la inmediación de los jueces en la actividad probatoria, es aquella denominada "prueba anticipada"; "que por sus características de producción — fuera de la instancia de juicio - provocan problemas de compatibilidad con los principios del modelo acusatorio y con algunas premisas constitucionales en que se apoya el modelo adversarial. (García, 2017)

El Artículo 502.2 del Código Orgánico Integral Penal, faculta al juzgador recibir como prueba anticipada los testimonios de las personas gravemente enfermas, de las físicamente imposibilitadas, de quienes van a salir del país, de las víctimas o testigos protegidos, informantes, agentes encubiertos y de todas aquellas que demuestren que no pueden comparecer a la audiencia de juicio. En el caso de audiencia fallida, y en los que se demuestre la imposibilidad de los testigos de comparecer a un nuevo señalamiento, el tribunal, podrá receptar el testimonio anticipado bajo los principios de inmediación y contradicción.

La prueba testimonial se práctica en la audiencia de juicio, ya sea en forma directa o a través de videoconferencia u otro medio de comunicación de similar tecnología, con excepción de las declaraciones anticipadas, modalidad que se puede utilizar tanto en materia procesal civil como en lo penal, tal como lo señalan los Artículos 174 y 502 numeral 10 del Código Orgánico General de Procesos como del Código Orgánico Integral Penal.

La modalidad de receptar la prueba anticipada a través de la cámara de Gesell ${ }^{2}$ también se prevé en la normativa ecuatoriana, para garantizar la no revictimización, el Código Orgánico Integral Penal dispone, en su Artículo. 510.- Reglas para el testimonio de la víctima.- La recepción del testimonio de la víctima deberá seguir las siguientes reglas: 1. La víctima previa justificación podrá solicitar a la o al juzgador se le permita rendir su testimonio evitando la confrontación visual con la persona procesada, a través de video conferencia, cámara de Gesell u otros medios apropiados para el efecto, sin que ello impida el derecho a la defensa y en especial, a contrainterrogar.

Igualmente, se faculta la versión o testimonio de niñas, niños o adolescentes, personas con discapacidad y adultos mayores ante el juzgador o fiscal, sea de forma adecuada a su situación y desarrollo evolutivo. Para el cumplimiento de este derecho se utilizarán elementos técnicos tales como circuitos cerrados de televisión, videoconferencia o similares, por una sola

\footnotetext{
${ }^{2}$ La cámara de Gesell es un dispositivo de experimentación que consiste en dos habitaciones, con una pared divisoria en la que hay un vidrio de gran tamaño, que permite ver desde una de las habitaciones lo que ocurre en la otra, pero no al revés. Recuperador en: http://www.ulacit.ac.cr/carreras/documentosulacit/psicologia/MANUAL\%20DE\%20FUNCIONAMIENTO\%20Y\% 20USOS\%20DE\%20LA\%20CAMARA\%20DE\%20GESELL\%20.pdf
} 
vez. Se incorporará como prueba la grabación de la declaración en la audiencia de juicio, tal como lo expresa el Artículo 504 del Código Orgánico Integral Penal.

El uso de video conferencia, como lo señala Gustavo Amoni:

Permite cumplir con las exigencias del principio de inmediación, siempre que la calidad de la imagen y el sonido sean suficientes para equipararse a una audiencia en presencia real ante el juez, puesto que ella permite a los presentes en la sala de audiencias, escuchar las declaraciones y observarlas, así como también que la persona que declara a distancia pueda observar lo que ocurre en la sala, en especial las reacciones del juez. Asimismo, este sistema de intercomunicación permite que el juez intervenga en la audiencia virtual e imponga su autoridad a quien declara, cuando fuera necesario, y todo en tiempo real, como si estuviera físicamente en la sala de audiencias. (Amoni, 2013).

Pero hay que tener en cuenta, que en ciertos casos, no es el mismo juez que recepta el testimonio anticipado, el que está presente en la audiencia de juicio, por lo que, no hay una interacción directa entre el testigo y el juez, y es el juez de juicio que debe revisar el audio y video de dicho testimonio con lo actuado en el mismo.

Como se citó anteriormente, la inmediación implica una comunicación directa entre el juez y las partes -inmediación subjetiva-; el contacto directo del juez con los hechos objeto de debate -inmediación objetiva- y su intervención directa en la práctica de las pruebas inmediación en la actividad-. (Bustamante, 2010), aunque Devis Echandia citando a Jaime Guasp señala a la inmediación de actividad que se presenta cuando se prescribe la proximidad o contacto del acto probatorio con otro acaecimiento distinto, que a su vez puede preceder, acompañar o seguir a la actividad de prueba, originándose de este momento los correspondientes, presupuestos, simultáneos y condiciones (Devis, Nociones Generales de Derecho Procesal Civil , 2009).

Resoluciones de la Corte Nacional de Justicia sobre la ausencia de juez en la audiencia de juicio Como el problema central de este trabajo es responder a la interrogante: ¿qué ocurre cuando uno o varios jueces, que estuvieron presentes en la audiencia donde se evacuó la actividad probatoria, pese a que emitieron su resolución oral, por cualquier circunstancia se ausentan definitivamente, no pueden suscribir la sentencia?, para contestar a la misma, es necesario analizar dos resoluciones obligatorias emitidas por el Pleno de la Corte Nacional de Justicia del Ecuador, la primera el 26 de octubre del 2011 y la segunda el 22 de noviembre del 2017, en base a la facultad prevista en el artículo 180 del Código Orgánico de la Función Judicial, para expedir resoluciones en caso de duda u oscuridad de las leyes, obligatorias, mientras no se disponga lo contrario por la Ley, y que rigen a partir de su publicación en el Registro Oficial.

La primera resolución del año 2011, se expidió en base a la consulta del Presidente de la Tercera Sala Especializada de lo Penal de la Corte Provincial de Justicia de Pichincha, que se cuestionaba: "Si los jueces de la Sala de lo Penal de la Corte Provincial de Justicia, que pronunciaron la correspondiente resolución en la audiencia oral, pública y contradictoria, son separados de sus funciones. ¿Los reemplazantes deben suscribir la sentencia escrita, de acuerdo 
con lo dispuesto en el Artículo 345 del Código de Procedimiento Penal, en el término de tres días, previa información mediante la lectura directa del proceso o a través de la escucha de la cinta magnetofónica desarrollada en la audiencia?"

El Pleno de la Corte Nacional de Justicia, emitió una resolución, publicada en el Registro Oficial No. 564, de 26 de octubre de 2011, que disponía en el Artículo 3:

A falta definitiva de los tres jueces que intervinieron en la audiencia, la sentencia será firmada por los tres conjueces respectivos, por lo que, en este caso, el ponente resultará de un sorteo interno, quien será el encargado de fundamentar y motivar la sentencia, tomando como base la lectura del proceso y/o la grabación magnetofónica según el caso, sin que pueda modificar, de manera alguna, la decisión tomada en la audiencia. De igual manera, el secretario sentará la razón sobre este particular.

Esto evidencia, que no era necesario que los jueces que no tomaron la decisión oral, inmedien con lo recepcionado en la prueba, sino que basta con argumentar la resolución, teniendo en cuenta la lectura de proceso, y la grabación magnetofónica.

Es decir, dicha resolución no cumple con lo que ordena el principio de inmediación que el tribunal del juicio perciba a través de sus propios sentidos, de forma directa, sin intermediarios, la información que proviene de la fuente directa donde ésta se encuentra registrada (Decap, 2014). Además, que la inmediación exige que el juez esté con todos sus sentidos, conocimientos y capacidad de análisis y de valoración probatorias en estado consciente y activo.

Sin embargo, el mismo Pleno sustituyó dicha resolución, señalando que en materias no penales y penales resultaba caduca, expidiendo la Resolución No. 18-2017 el 22 de noviembre del 2017, mediante la cual, estableció: “Artículo 4.- Si la ausencia es definitiva de uno o más jueces o juezas, el juez o jueza que esté actuando en el tribunal, comunicará al Presidente de la Corte Nacional de Justicia o al Director del Consejo de la Judicatura de cada Provincia, según el caso, para que, previo sorteo, designe un conjuez o conjueza, juez o jueza, que complete el tribunal; $y$, de este modo, resuelva lo pertinente.

Si se produce la ausencia definitiva de un juez o jueza unipersonal, el secretario de la unidad judicial o de la Sala, informará del particular al Presidente de la Corte Nacional o al Director Provincial del Consejo de la Judicatura, según corresponda, para que designe el conjuez o conjueza, juez o jueza que deberá asumir la competencia y emitir la resolución que corresponda".

Resolución que dispone que se debe designar a otro juez para que expida la sentencia, quien no puede cambiar lo decidido en audiencia, aunque no haya estado presente en la misma, sin haber presenciado la introducción y práctica de pruebas, por lo que aquí es necesario, tener en cuenta lo señalado por Álvaro Mejía Salazar, que, conviene ponderar a la inmediación por encima de la economía y celeridad (Mejía, La oralidad y los principios del procedimiento, 2018), además por cuanto, el mismo juez que debe dictar la sentencia deberá escuchar las respuestas de las partes, las deposiciones de los testigos, las explicaciones de los peritos, examinará los objetos, visitará los lugares, entrando así en contacto inmediato con las fuentes de su 
convencimiento. (Palomo R. A., 2009). Muy diferente a lo que ocurre en el sistema español donde, si existe algún procedimiento superviniente que obste al juez que presenció la comparecencia para resolver la causa, los Arts. 199 y 200 de la Ley de disponen la obligatoriedad de celebrar una nueva vista, que deberá ser presenciada por el juez que sustituya al impedido. (Mejía, La oralidad y los principios del procedimiento, 2018).

Previo a dictar la Resolución No. 18-2017, la aludida Corte emitió algunos fallos en materia penal, en los cuales declaró la nulidad a partir de la audiencia de juzgamiento, ordenando que otro tribunal realice una nueva audiencia, no obstante, dicha resolución es contraria a dichos fallos, aún más que existe la disposición contenida en el Artículo 72 del Código Orgánico General de Procesos, donde se faculta al juzgador ordenar la práctica de diligencias mediante comisión o deprecatorio, pero en ningún caso la realización de audiencias ni la práctica de pruebas, por lo que, en primer término dicha resolución constituiría una contradicción a los fines del sistema oral y por ende al principio de inmediación.

Así, en el caso No. 343-2013, Resolución, 367-2013, la Sala de lo Penal de la Corte Nacional, señaló que la Sala que sustanció el recurso, al integrarla con otro conjuez que no estuvo en la audiencia oral, pública y contradictoria, se vulneró el derecho a la tutela efectiva, imparcial y expedita, declarando la nulidad de lo actuado desde la audiencia de fundamentación del recurso de apelación.

En el Juicio No. 1041-2012-LBP, la misma Sala de lo Penal, de la indicada Corte, declara la nulidad de lo actuado a partir de la audiencia oral, pública y contradictoria, por cuanto la audiencia oral, pública y contradictoria que se realiza para conocer el recurso de apelación, constituye un solo acto desde su instalación hasta la resolución, siendo competentes única y exclusivamente los jueces que conocieron del recurso en la audiencia, en atención a los principios legales y constitucionales de inmediación y contradicción, expresando además, que está inobservancia legal y constitucional acarrea la invalidez de lo actuado e incurre en la causal de nulidad prevista en el Artículo 330 del Código Procedimiento Penal que decía: Habrá lugar a la declaración de nulidad, en los siguientes casos: (...) 3. Cuando en la sustanciación del proceso se hubiere violado el trámite previsto en la ley, siempre que tal violación hubiere influido en la decisión de la causa".

En el caso No. 526-2014, de 11 de abril de 2014, la Sala de lo Penal de la Corte Nacional de Justicia, declara la nulidad de lo actuado desde la audiencia de fundamentación del recurso de apelación, La sentencia fue suscrita por una jueza y dos jueces que no intervinieron en la audiencia oral, reservada y de contradictorio de sustentación del recurso de apelación, vulnerando derechos como el de la defensa y tutela judicial efectiva y el principio de inmediación. Además, dicha sentencia hace referencia a lo pronunciado por la ex-Corte Constitucional para el Periodo de Transición en la sentencia No. 021-12 -SEP-CC, caso No. 0419-11 -EP, que el principio de inmediación, que refiere a la presencia del juzgador en las diligencias procesales, esto es, está encaminado a la relación directa con los litigantes, a la apreciación inmediata de las pruebas llevadas al proceso, que no es soslayado por el hecho de emitir un voto salvado.

La Corte Constitucional, en el caso No. 1221-14-EP, estableció que: 
A través de la inmediación se da una vinculación personal entre los juzgadores y las partes con la finalidad de poder conocer directamente todo lo correspondiente al proceso penal, desde su inicio hasta su conclusión, de tal forma que se tenga un conocimiento efectivo de los hechos planteados para su resolución por parte de los administradores de justicia, obteniendo los medios y elementos para que el proceso sea eficaz y la sentencia justa.

La Sala Penal de la Corte Nacional de Justicia, en el año 2016, dentro del proceso No. 17721-2016-0206, expresó:

La oralidad y la inmediación, obligan al juzgador a efectuar su razonamiento jurídico al finalizar la intervención de los sujetos procesales, en el llamado acto de la deliberación, en el que se analiza con argumentos fácticos o jurídicos (dependiendo del caso) la viabilidad de conceder las pretensiones del peticionario, o aceptar las excepciones de su contraparte. Es este proceso ininterrumpido que se genera en las audiencias, sujetas a la oralidad, el que impide, en definitiva, que sea otro juzgador el que motive por escrito lo que ya fue decidido en forma verbal por sus antecesores, pues aunque resulten replicables (mediante actas o grabaciones magnetofónicas) las aseveraciones de los litigantes, es improbable que el nuevo órgano jurisdiccional pueda reproducir todos los motivos y razones que confluyeron en la mente de cada uno de los jueces que conformaron el tribunal, o inclusive las que, una vez exteriorizadas, fueron motivo de debate entre ellos para optar por la decisión final; lo que se debe, fundamentalmente, a la privacidad generalizada en la que se lleva a cabo el acto de la deliberación.

La Sala Penal de la Corte Provincial de Justicia de Loja, dentro del proceso No. 112822015-00623, resolvió anular el proceso desde la audiencia de juicio, quedando el proceso en estado de que se vuelva a celebrar la audiencia de juzgamiento, por cuanto dos jueces no han inmediado en la audiencia de juicio, manifestando que la inmediación, impide, en definitiva, que sea otro juzgador el que motive por escrito lo que ya fue decidido en forma verbal por sus antecesores, y continúa con los mismos argumentos que la resolución de la Corte Nacional dentro del proceso 17721-2016-0206.

\section{Discusión de resultados}

El principio de inmediación constituye un postulado fundamental del sistema procesal oral y por ende de la actividad probatoria, en virtud del cual el juez que resuelva la causa debe ser el que mantuvo los contactos directos con los partícipes del proceso, el COGEP no lo prevé de manera expresa. No obstante, en atención al modelo hiper concentrado observado por la normativa ecuatoriana, que establece la obligatoriedad de resolver el caso en la misma comparecencia - art 93-, se aseguraría la observancia de este postulado. (Mejía, La oralidad y los principios del procedimiento, 2018).

El artículo 93 del Código Orgánico General de Procesos COGEP, determina que el finalizar la audiencia la o al juzgador pronunciará su decisión en forma oral, asimismo el artículo 610 del Código Orgánico Integral Penal establece que en el juicio regirán los principios de oralidad, publicidad, inmediación y contradicción en la actuación probatoria; sin embargo, las 
resoluciones dictadas por el Pleno de la Corte Nacional de Justicia no garantizan este principio, por lo que, resulta necesario expulsar del ordenamiento jurídico las mismas.

\section{Conclusiones}

Uno de los principios fundamentales de un sistema procesal oral por audiencias es la inmediación que implica al juez interactuar en la recepción de la prueba, permitiéndole tomar una decisión basada en la información de calidad proporcionada por las partes, testigos y peritos.

A través de la inmediación se logra que el juez extraiga su convicción sobre la prueba actuada en audiencia.

Las Resoluciones dictadas por la Corte Nacional de Justicia del Ecuador, en caso de ausencia de alguno de los jueces, que intervinieron en el juicio oral y que por cualquier circunstancia no pudieron suscribir la sentencia, vulneran el principio de inmediación, por cuanto, no permiten que el juez interactúe en la misma, ni dicte una sentencia formando su convicción.

Tomar una decisión judicial sin haber intervenido en una audiencia por parte de los juzgadores, es hacer referencia a un sistema escrito, en donde el juzgador debe extraer sus conclusiones sobre lo constante en actas o en la escucha del audio o video.

A la luz del principio de inmediación, los fundamentos jurídicos de las resoluciones expedidas por la Corte Nacional de Justicia, son insostenibles en el derecho probatorio, por lo que, deberían derogarse, y tener en cuenta la esencia de este principio, lo que podría hacer el legislador, incluir alguna disposición tanto en el Código Orgánico General de Procesos como en el Código Orgánico Integral Penal, en el sentido que en ausencia del juez que no estuvo presente en la audiencia oral, debería celebrarse otra audiencia con otros jueces que deben intervenir en la misma, así como en la suscripción de la decisión escrita, esto con el fin de garantizar la tutela judicial efectiva y el acceso a la justicia de los ciudadanos.

\section{Bibliografía}

Aguirrezabal, M. (2017). El principio dispositivo y su influencia en la determinación del objeto del proceso en el proceso civil chileno. Revista de Derecho Privado, 424.

Amoni, G. A. (2013). El uso de la videoconferenca en cumplimiento del principio de inmediación procesal. Revista del Instituto de Ciencias Jurídicas de Puebla, 85.

Bustamante, M. (2010). La oralidad en el sistema penal acusatorio colombiano. En U. d. Medellín, Oralidad y proceso. Una perspectiva desde Iberoamérica (pág. 100). Medellin.

Cabanellas de Torres, G. (2012). Diccionario de Ciencias Jurídicas. Buenos Aires: Heliasta.

Centro de Estudios de Justicia de las Américas. (2013). APORTES PARA UN DIÁLOGO SOBRE EL ACCESO A LA JUSTICIA Y REFORMA CIVIL. Santiago. 
Decap, M. (2014). El juicio oral y los principios de inmediación y. Revista del Instituto de la Judicatura Federal, 69.

Devis, H. (2009). Nociones Generales de Derecho Procesal Civil. Bogotá: Editorial Temis.

Devis, H. (2009). Nociones Generales de Derecho Procesal Civil. Bogotá: Temis.

Duce, A. B. (2004). Litigación penal, juicio oral y prueba.

García, M. (2017). Los problemas de inmediación judicial en los casos de prueba anticipada. Actualidad Penal, 4.

Martínez Lina, P. M., \& Diaz Laura, M. H. (2009). Debido proceso, inmediación, derecho de defensa, su observancia en un proceso civil oral. Iter ad Veritatem, 93.

Martínez, L. P. (2009). Debido proceso, inmediación, derecho de defensa, su observancia en un proceso civil oral. Revista Iter ad Veritatem, 93.

Mejía, A. (2018). La oralidad y los principios del procedimiento. Quito: Ecuador, F.B.T. Cía. Ltda.

Mejía, A. (2018). La oralidad y los principios del procedimiento. Quito: Ecuador F.B.T. Cía. Ltda.

Palomo, D. (2009). Las marcas del proceso oral y escrito diseñado en el proyecto de nuevo CPC Chileno. Revista Chilena de Derecho, 628.

Palomo, R. A. (2009). Oralidad y prueba: comparación y análisis crítico de las experiencias reformadoras del proceso civil en Alemania y España. Revista de Derecho de la Pontificia Universidad Católica de Valparaíso, 403.

Pereira Santiago, V. C. (2011). Bases generales para una Reforma a la Justicia Civil en América Latina y el Caribe. En Modernización de la justicia civil (pág. 63). Montevideo: Tradinco S.A.

Roxin, C. (2008). Derecho Procesal Penal. Buenos Aires: Editores del Puerto.

Zabaleta, Y. (2017). La contradicción en materia probatoria, en el marco del proceso penal colombiano. Rev. CES Derecho, 4.

\section{Normativa:}

Constitución de la República del Ecuador, RO 1 de 11-ago-1998.

Constitución de la República del Ecuador, 2008, RO 0499 de 20-oct-2008. Código Orgánico General de Procesos, RO-S, 506: 22-may-2015.

Código Orgánico de la Función Judicial, RO-S, 544 de 09-mar.-2009

Código Orgánico Integral Penal, RO-S, 180, de 10-feb-2014.

Jurisprudencia:

Proceso 17721-2016-0206 de 6 de febrero del 2017, Sala Especializada de lo Penal, Penal Militar, Penal Policial y Tránsito de la Corte Nacional de Justicia. 